EPJ Web of Conferences 44, 02001 (2013)

DOI: $10.1051 /$ epjconf/20134402001

(C) Owned by the authors, published by EDP Sciences, 2013

\title{
NUMERICAL STUDY OF HEAT TRANSFER FROM A WALL INCORPORATING A PHASE CHANGE MATERIAL
}

\author{
L. DERRADJI ${ }^{1,2}$, A. HAMID $^{2}$, B. Zeghmati ${ }^{3}$, M. Amara ${ }^{1}$, A. BOUTTOUT ${ }^{1}$, Y. MAOUDJ $^{1}$
}

\author{
${ }^{1}$ National Center of Studies and Integrated Research on Building Engineering (CNERIB), Cité Nouvelle El Mokrani, \\ Souidania, Algiers, Algeria. \\ ${ }^{2}$ Department of Mechanical Engineering, University of Blida, BP 270 route de soumma, Blida, Algeria. \\ ${ }^{3}$ Department of Mathematics and Physics, University of Perpignan Via a Domiti, 52 avenue Paul Alduy 66860 \\ Perpignan Cedex, France.
}

\begin{abstract}
A numerical study of the thermal behavior of walls made up of construction materials used in Algeria and walls containing a phase change materials is presented. The model, based on the enthalpy formulation, is described by an equation of heat transfer. This equation is solved by an implicit method of finite differences and algorithm of Thomas. We analyzed the influence of the wall's thickness and its composition on the evolution during the time of the temperature of the inside face of thewall.
\end{abstract}

\section{Introduction}

The building sector in Algeria is one of the most dynamic sectors, result of a high rate of growth of the population and urbanization. The growth of the population in Algeria is remarkable, increasing from 18,8 million inhabitants in 1980 to 34,4 million in 2008 . Consequently, the request for housing increases considerably and is making construction one of the main engines driving the growth of the country.

In Algeria, the building sector is the largest energy consumer among the economic sectors, with $41 \%$ from national energy and $21 \%$ of the $\mathrm{CO} 2$ emission [1]. Most of this energy comes from heating and air-conditioning systems. It thus proves necessary to reduce the share of energy used in the building sector and thus the environmental impact of this sector by promoting concept of buildings with low energy intake.

The thermal inertia of the building plays a significant role in the improvement of thermal comfort and the reduction of energy consumptions in the building sector [2]. The techniques based on thermal inertia contribute to improve thermal comfort and to allow energy savings. Also, the integration of phase change materials (PCM) in building was the purpose of many researchers who analyzed their impacts on the energy efficiency of the envelope of a building. Maha et al. [3,4] carried out tests by incorporating PCM coupled with the use of a super insulation material VIP (Vacuum Insulation Panel) in walls made up of PVC. The concept of coupling PCM with a super insulation material proves to be a promising solution for light envelopes of low thickness having a good insulation and a significant inertia. The determination, with the software CODYMUR, of the optimal thickness of a plasterboard in which a PCM has been added, showed that a one $\mathrm{cm}$ thickness can double the thermal inertia of this plate [5].

Castellón et al. [6] proved the feasibility of the use of the micro PCM encapsulated (Micronal BASF) in sandwich panels to increase their thermal inertia and to reduce the energy demand of the buildings. An experimental study on two prototypes, on scale 1 , of exchangers of heat PCM-air intended for natural ventilation in buildings showed that this type of exchanger can ensure the natural cooling of a house with a low thermal conductivity of the PCM [7].

This work deals with a numerical study of the thermal behavior of walls built with construction materials used in Algeria and in which PCM were added. The model, based on the enthalpy formulation, is described by an equation of heat transfer which we solved by an implicit method of finite differences and the algorithm of Thomas. We analyzed the influence of wall thickness and its composition as well as the effect of PCM materials on

* lotfi.derradjieyahoo.fr 
the evolution during the time of the temperature of the wall inner face. The results obtained from the model were confronted with the results of a similar study of Maha Ahmed et al. [3,4]. Confrontation shows a good agreement.

\section{Physical model and mathematical formulation}

\section{1 Physical model}

Let us consider a vertical wall with a thickness $\mathbf{e}$ in which a phase change material (PCM) is built-in. This wall is between the inside environment characterized by a temperature fixed at $23{ }^{\circ} \mathrm{C}$, and the external environment which has sinusoidally varying temperature with which it heat transfers by convection (figure 1).

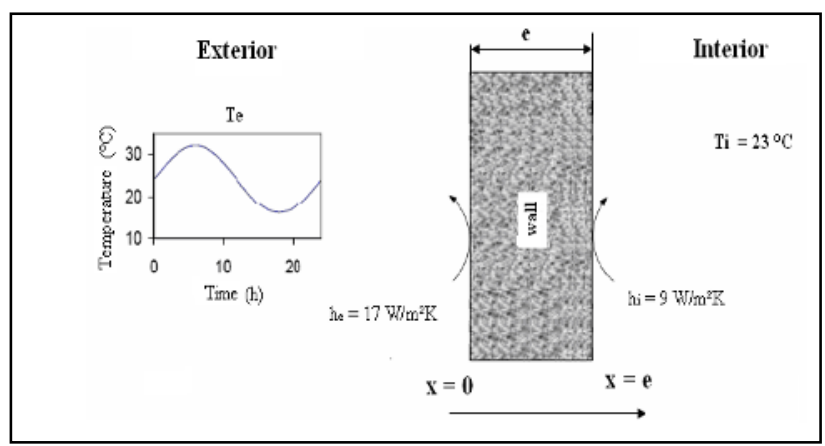

Fig.1. Diagram of the physical model

\section{2 mathematical formulation}

\subsubsection{Assumptions}

- The heat transfer is unidirectional;

- The thermo-physical properties of homogeneous materials are constant.

- The thermo-physical properties of mixture plaster /PCM are variable.

Considering the formulated assumptions above, the equation of transfer verifies the following expression [8]:

$$
\rho \mathrm{k} \frac{\partial \mathrm{h}_{\mathrm{k}}}{\partial \mathrm{t}}=\lambda_{\mathrm{k}} \frac{\partial^{2} \mathrm{~T}}{\partial \mathrm{x}^{2}}
$$

$h_{k}$ : enthalpy of the layer $k$ of the wall.

For the homogeneous materials as the plaster, the concrete, the BTS and the stone, the drifted partial of the enthalpy is given by [8]:

$$
\frac{\partial \mathrm{h}_{\mathrm{k}}}{\partial \mathrm{t}}=\mathrm{C}_{\mathrm{k}} \frac{\partial \mathrm{T}}{\partial \mathrm{t}}
$$

$\mathrm{C}_{\mathrm{k}}$ : specific heat.

For a wall in plaster containing a PCM material, the equation (1) is written [8]:

$$
\frac{\partial h_{P C M}}{\partial \mathrm{t}}=\frac{\partial h_{P C M}}{\partial \mathrm{T}} \frac{\partial \mathrm{T}}{\partial \mathrm{t}}=\mathrm{C}_{\mathrm{PCM}}(\mathrm{T}) \frac{\partial \mathrm{T}}{\partial \mathrm{t}}
$$

For the considered mixture (plaster 70\%, GR 30\%), the specific heat of this mixture varies according to the temperature [3,4], as it is reported on the figure 2 .

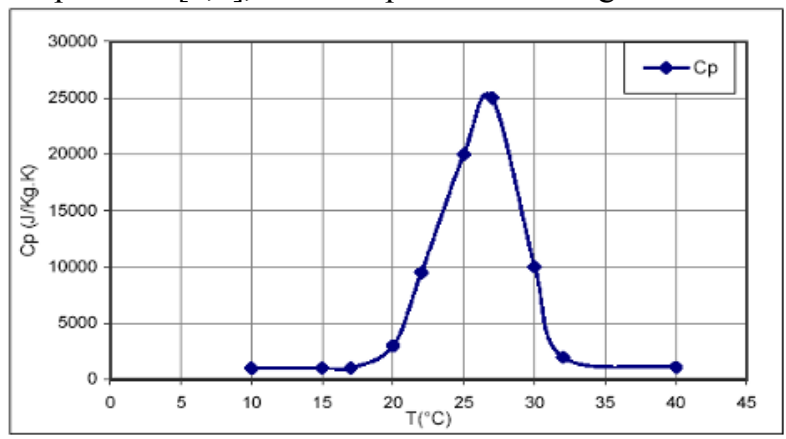

Fig. 2. Evolution of the specific heat capacity of a mixture Plasters / PCM (30\%) according to its temperature $[3,4]$.

\subsection{Initial conditions and Boundaries conditions}

\subsubsection{Initial conditions}

$\forall \mathrm{t}<\mathrm{t} 0$, $\mathrm{t} 0$ is the instant from which the wall is exposed to heat transfers by convection; $\mathrm{T}(\mathrm{x}, \mathrm{t})=\mathrm{Tin}$;

Tin $=23{ }^{\circ} \mathrm{C}$, where Tin the initial temperature

\subsubsection{Boundaries conditions}

$\forall \mathrm{t}>\mathrm{t} 0$

at $\mathrm{x}=0$, Fourier-type boundaries conditions:

$$
-\left.\lambda \frac{\partial \mathrm{T}}{\partial \mathrm{x}}\right|_{\mathrm{X}=0}=\mathrm{h}_{\mathrm{e}}\left(\mathrm{T}_{\mathrm{e}}-\mathrm{T}(0, \mathrm{t})\right)
$$

With:

- An outer temperature varying sinusoidally according to the relation:

$$
\mathrm{T}_{\mathrm{e}}(\mathrm{t})=24+8 \sin \left(7.2710^{-5} \mathrm{t}\right)
$$

- A coefficient of heat exchange between the outer wall and the atmosphere [9]:

$$
\mathrm{he}=17\left[\mathrm{~W} / \mathrm{m}^{2} \mathrm{~K}\right]
$$

at $\mathrm{x}=\mathrm{e}$, Fourier-type boundaries conditions:

$$
-\left.\lambda \frac{\partial \mathrm{T}}{\partial \mathrm{x}}\right|_{\mathrm{X}=\mathrm{e}}=\mathrm{h}_{\mathrm{i}}\left(\mathrm{T}(\mathrm{e}, \mathrm{t})-\mathrm{T}_{\mathrm{i}}\right)
$$

With :

- A constant inside temperature:

$$
\mathrm{Ti}=23\left[{ }^{\circ} \mathrm{C}\right]
$$

- A coefficient of heat exchange between the interior wall and the interior air [9]:

$$
\mathrm{hi}=9\left[\mathrm{~W} / \mathrm{m}^{2} \mathrm{~K}\right]
$$

\subsection{Numerical Methodology}

In order to solve the nonlinear differential equation which governs heat transfer through a wall integrating an PCM material, the method of finite differences according to an implicit scheme was established. Discretiszation of the equation (1) leads to the following expression :

$$
\rho_{i} C_{i}^{n} \frac{T_{i}^{n+1}-T_{i}^{n}}{\Delta t}=\lambda_{i}\left(\frac{T_{i-1}^{n+1}-2 T_{i}^{n+1}+T_{i+1}^{n+1}}{\Delta x^{2}}\right)
$$


The equation (7) written for each point $1<\mathrm{i}<\mathrm{N}$ results in a system with $\mathrm{N}$ simultaneous equations and $\mathrm{N}$ unknown factors. We obtained a system of tridiagonal algebraic equations, which we solved with Thomas Algorithm.

\section{Composition of the walls}

We considered walls in: plaster, concrete, stabilized earth brick Brick (BTS), stone, as well as walls made up of a mixture plasters /PCM

Tables 1 and 2 represent thermal conductivity values $(\lambda)$, density $(\rho)$ and the specific heat $(C)$ of various materials studied in this article.

Table 1. Thermo physical properties of studied materials

\begin{tabular}{|l|l|l|l|}
\hline Materials & $\rho(\mathrm{kg} / \mathrm{m} 3)$ & $\lambda(\mathrm{W} / \mathrm{m} . \mathrm{k})$ & $\mathrm{C}(\mathrm{J} / \mathrm{kg} . \mathrm{k})$ \\
\hline Plaster & 1000 & 0,35 & 936 \\
\hline Concrete & 2200 & 1,75 & 1080 \\
\hline BTS & 2000 & 1,3 & 1325 \\
\hline Stone & 2340 & 1,4 & 936 \\
\hline
\end{tabular}

Table 2. Thermo physical properties of the plasters/PCM mixture $[3,4]$

\begin{tabular}{|l|l|l|l|l|}
\hline \multicolumn{1}{|c|}{ Materials } & Concentration & State & $\begin{array}{c}\mathrm{C} \\
(\mathrm{J} / \mathrm{kg} . \mathrm{K})\end{array}$ & $\begin{array}{c}\lambda \\
(\mathrm{W} / \mathrm{m} . \mathrm{K})\end{array}$ \\
\hline $\begin{array}{l}\text { Plaster/ } \\
\text { GR25 }\end{array}$ & $30 \%$ & Solid & 1217,7 & 0,2602 \\
\hline Plaster/GR25 & $30 \%$ & Liquid & 1368,1 & 0,2639 \\
\hline
\end{tabular}

\section{Results and discussion}

We analyzed the influence of these walls thickness by considering a thickness ranging between $1 \mathrm{~cm}$ and $8 \mathrm{~cm}$. the calculations were carried out for an interior temperature $\mathrm{Ti}=23^{\circ} \mathrm{C}$ and an outside air temperature

$$
T_{e}(t)=24+8 \sin \left(7.2710^{-5} t\right)
$$

The convection heat transfer coefficients between the wall and ambient air (he) and between the wall and the interior air (hi) are respectively equal to $17 \mathrm{~W} / \mathrm{m}^{2} . \mathrm{K}$ and $9 \mathrm{~W} / \mathrm{m}^{2} . \mathrm{K}$. From Figure 3, we see the effect of PCM on the thermal stability of wall's inner face made up of plaster and PCM. The temperature of the wall's inner face, thickness equal to $1 \mathrm{~cm}$, varies between 18,8 and $26,5^{\circ} \mathrm{C}$ with a time lag of $3,5 \mathrm{~h}$. For a thickness equal to $8 \mathrm{~cm}$, the temperature is almost constant during the day; with a very small variation with time (lower than $1^{\circ} \mathrm{C}$ ). Let us note that the temperature of the inner face of the wall is close to $23{ }^{\circ} \mathrm{C}$, this value contributes to improve thermal comfort of a habitat whose walls would be submitted to the same climatic conditions as the wall retained in this study. We note that the variation, during the time, of the wall inner face temperature decreases with the increase its thickness and that for a thickness at least equal to $3 \mathrm{~cm}$, the time lag is very high. Thus, for a $3 \mathrm{~cm}$ thickness, time lag is estimated at 8:00 and for a thickness equal to $5 \mathrm{~cm}$ it is $12 \mathrm{~h}$.

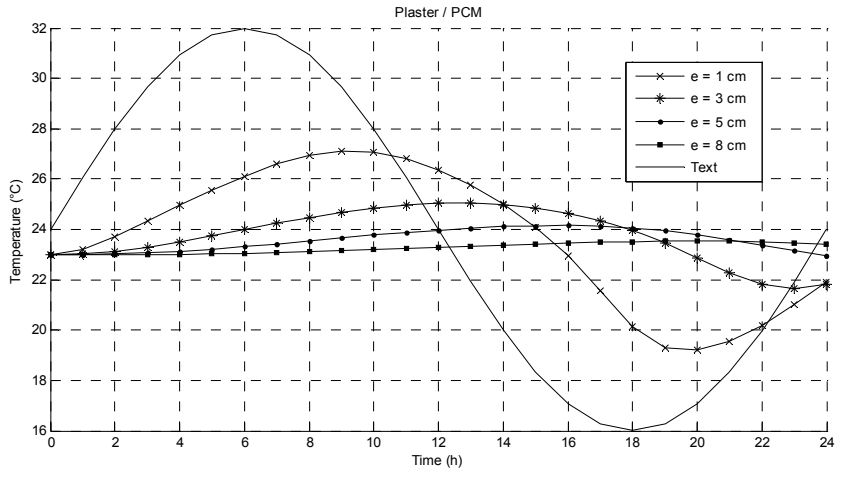

Fig. 3. Indoor surface temperature variation for plaster/PCM walls

Figure 4 illustrates the evolution during the time of the temperature of the inner face of a plaster wall according to the thickness (e). For a thickness equal to $1 \mathrm{~cm}$, the temperature is set between 19 and $28^{\circ} \mathrm{C}$ with amplitude, defined by the difference between the maximum and minimal temperatures of the day, equal to $9^{\circ} \mathrm{C}$. For a 8 $\mathrm{cm}$ thickness, it oscillates during time between a minimal value of 21 and one maximum value of $25,5^{\circ} \mathrm{C}$, with an amplitude of $4,5^{\circ} \mathrm{C}$. We note that just like the preceding case, the amplitude of the temperature of interior surface decreases with the increase of its thickness.

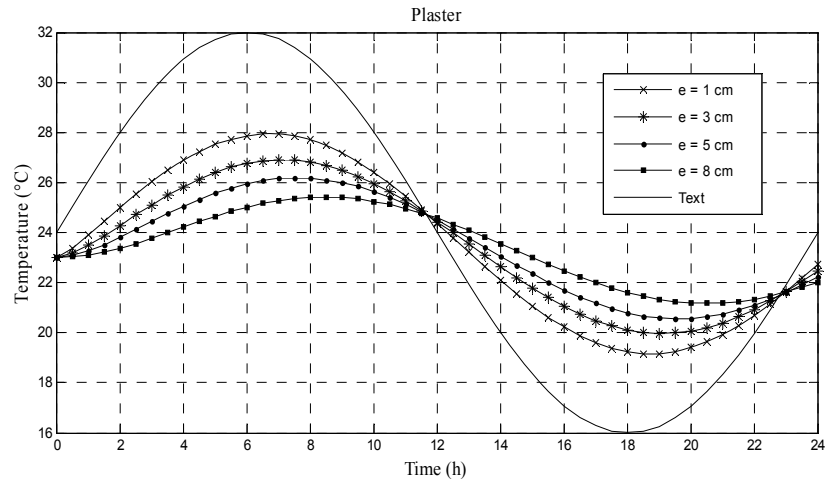

Fig. 4. Indoor surface temperature variation for plaster walls

Figure 5 illustrates the evolution during a day of the temperature of the inner face of a concrete wall according to its thickness. For a thickness equal to $1 \mathrm{~cm}$, the temperature varies from 18,8 to the $28,8{ }^{\circ} \mathrm{C}$ with an amplitude of $9{ }^{\circ} \mathrm{C}$; it lies between 20 and $27{ }^{\circ} \mathrm{C}$ for a thickness equal to $8 \mathrm{~cm}$. It follows a 2,2 hours time lag between the outside temperature and that of the inner face wall.

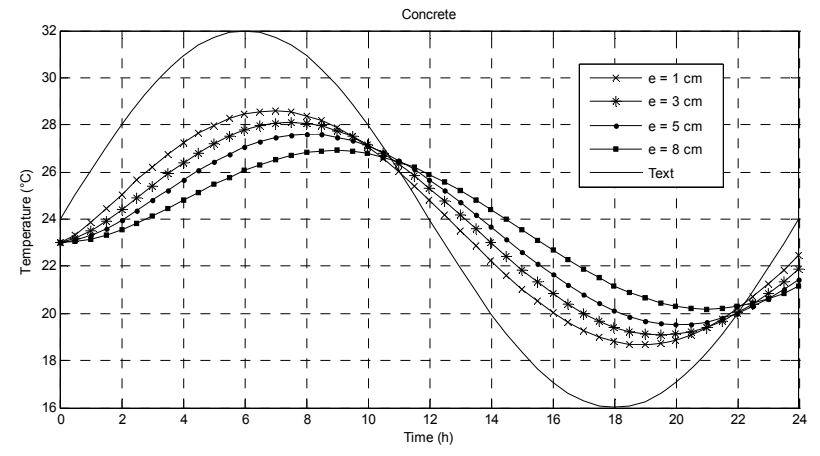

Fig. 5. Indoor surface temperature variation for Concrete walls 
For a wall made up of stabilized earth brick of a thickness equal to $1 \mathrm{~cm}$, the variation in the temperature of its inner face lies between 18,8 and $28,8^{\circ} \mathrm{C}$ with an amplitude of $10{ }^{\circ} \mathrm{C}$ (figure 6). The amplitude is reduced to $6^{\circ} \mathrm{C}$ for a thickness equal to $8 \mathrm{~cm}$ and this temperature varies between 20,5 and $26,5^{\circ} \mathrm{C}$.

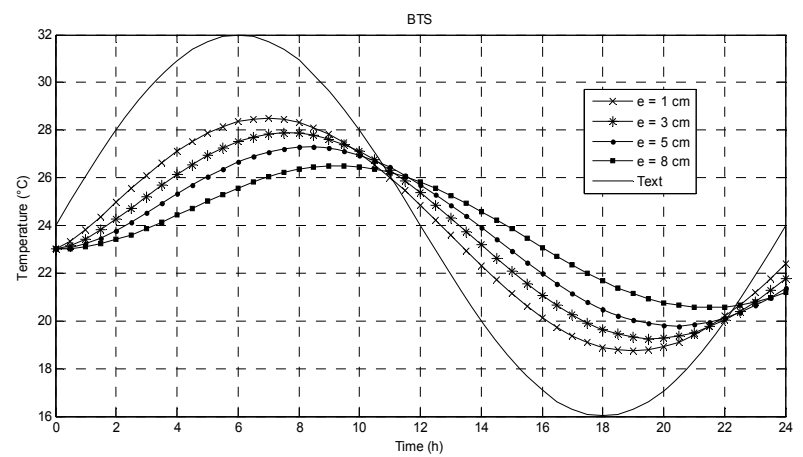

Fig. 6. Indoor surface temperature variation for walls in BTS

The temperature of the inner face of a stone wall, varies from 18,8 to $28,5{ }^{\circ} \mathrm{C}$ with an amplitude of $10{ }^{\circ} \mathrm{C}$ for a thickness equal to $1 \mathrm{~cm}$ and oscillates between a minimal value of 22,2 and one maximum value of $26,8^{\circ} \mathrm{C}$, with an amplitude of $4,6^{\circ} \mathrm{C}$ for a thickness equal to $8 \mathrm{~cm}$ (figure 7).

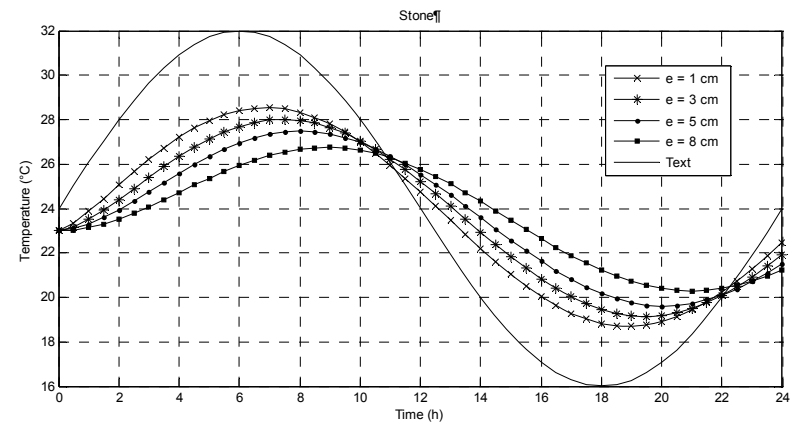

Fig. 7. Indoor surface temperature variation for stone walls

\section{Conclusion}

By using the model based on the enthalpy formulation, we proceeded to a numerical study of the thermal behavior of a wall made up of construction materials and PCM. We showed that a wall made up of plaster and MPC of thickness equal to $8 \mathrm{~cm}$ can stabilize the temperature of its inner face during 24 hours, with a very low amplitude (lower than $1^{\circ} \mathrm{C}$ ).

For other construction materials, it varies between 20 and $26{ }^{\circ} \mathrm{C}$, with a time lag compared to the outside air temperature with a maximum period equal to 3 a.m. and of the amplitudes of temperature varying between 5 to 7 ${ }^{\circ} \mathrm{C}$.

\section{Nomenclature}

$\begin{array}{lll}\text { C } & \text { Specific Heat } & \mathrm{J} / \mathrm{kg} \mathrm{K} \\ \mathrm{e} & \text { Wall's thickness } & \mathrm{m} \\ \mathrm{h} & \text { Enthalpy } & \mathrm{J} / \mathrm{kg} \\ \text { he } & \begin{array}{l}\text { Internal convective heat transfer } \\ \text { coefficient }\end{array} & \mathrm{W} / \mathrm{m}^{2} \\ & \begin{array}{l}\text { External convective heat transfer } \\ \text { coefficient }\end{array} & \mathrm{W} / \mathrm{m}^{2} \\ & & \mathrm{~K}\end{array}$

$\begin{array}{lll}t & \text { Time } & \mathrm{s} \\ T & \text { Temperature } & { }^{\circ} \mathrm{C} \\ \lambda & \text { Thermal conductivity } & \mathrm{W} / \mathrm{m} \mathrm{K} \\ \rho & \text { Density } & \mathrm{kg} / \mathrm{m}^{3} \\ \Delta \mathrm{t} & \text { Time interval } & \mathrm{s} \\ \Delta \mathrm{x} & \text { Interval of distance } & \mathrm{m}\end{array}$

Subscripts

PCM Phase change Materials

e Outside

$i \quad$ Inside

$k \quad$ Layer of a wall

\section{References}

1. Consommation énergétique finale de l'Algérie, APRUE, Ministry for energy and the mines, Algeria, Edition 2009.

2. L. DERRADJI et al, Etude expérimentale du comportement thermique d'une maison rurale à faible consommation d'énergie", JITH 2011, university of Tlemcen, Algeria, September 2011.

3. Ahmad M, Bontemps A, Salle H, Quenard D. Experimental investigation and computer simulation of thermal behaviour of wallboards containing a phase change material. Energy and Buildings 2006;38(4):35766.

4. Ahmad M, Bontemps A, Salle H, Quenard D. Thermal testing and numerical simulation of a prototype cell using light wallboards coupling vacuum isolation panels and phase change material. Energy and Buildings 2006;38(6):673-81.

5. Kuznik F, Virgone J, Noel J. Optimization of a phase change material wallboard for building use. Applied Thermal Engineering 2008; 28(11-12):1291-8.

6. C Castellón, M Medrano, J Roca, F. Cabeza, Maria E. Navarro, A I. Fernández ,A. Lázaro, B. Zalba. Effect of microencapsulated phase change material in sandwich panels. Renewable Energy 35 (2010) 2370-4.

7. A Lazaro, P Dolado, Jose M. Marín, B Zalba, PCM-air heat exchangers for free-cooling applications in buildings: Experimental results of two real-scale prototypes. Energy Conversion and Management 50 (2009) 439-43.

8. F. Kuznik, J. Virgone, J. Roux. Energetic efficiency of room wall containing PCM wallboard: A full-scale experimental investigation. Energy and Buildings 2008;40 (8):148-56.

9. DTR C3-2, Réglementation thermique des bâtiments d'habitation, Règle de calcul des déperditions calorifiques, CNERIB, Algiers, December 1997. 